Article

\title{
A New Extract from Pomegranate (Punica granatum L.) By-Products as a Potential Oenological Tannin: Preliminary Characterization and Comparison with Existing Commercial Products
}

\author{
Valentina Canuti ${ }^{1}\left(\mathbb{D}\right.$, Lorenzo Cecchi ${ }^{2, *}{ }^{\oplus}$, Mohamad Khatib ${ }^{2}{ }^{\infty}$, Lorenzo Guerrini ${ }^{1}{ }^{(}$, \\ Nadia Mulinacci ${ }^{2}$ and Bruno Zanoni ${ }^{1}$ (D) \\ 1 DAGRI-Department of Agricultural, Food, Environmental, and Forestry Sciences and Technologies, \\ University of Florence, via Donizetti, 6-50144 Firenze, Italy; Valentina.canuti@unifi.it (V.C.); \\ lorenzo.guerrini@unifi.it (L.G.); Bruno.zanoni@unifi.it (B.Z.) \\ 2 Department of Neurosciences, Psychology, Drug Research and Child Health (NEUROFARBA), Division of \\ Pharmaceutical and Nutraceutical Sciences, University of Florence, via U. Schiff 6, 50019 Sesto Fiorentino, \\ Italy; mohammadtttt@yahoo.com (M.K.); nadia.mulinacci@unifi.it (N.M.) \\ * Correspondence: lo.cecchi@unifi.it; Tel.: +39-055-4573707
}

Academic Editors: Marchetti Nicola and Giuseppina Paola Parpinello

Received: 27 August 2020; Accepted: 28 September 2020; Published: 28 September 2020

check for updates

\begin{abstract}
Oenotannins are nowadays widely used as co-adjuvant in the winemaking process. The increasing cultivation and consumption of pomegranate (Punica granatum L.) leads to high amounts of by-products, mainly peels. Aim of this study was to propose a dried tannin-rich extract from pomegranate by-products as a new oenotannin. A decoction was prepared from mesocarp of the Wonderful pomegranate variety only using hot water as extracting solvent. The dried decoction was physical-chemically characterized and compared to 7 existing commercial oenotannins from different botanical origin (grape seed, oak, gallnut), according to UV-Vis Spectroscopy, Colorimetric analysis (CIELab), gelatin index, reactivity to proteins, HPLC-DAD, DPPH, and Total Polyphenols content by both Folin-Ciocalteu and the International Organization of Vine and Wine (OIV) methods. Data showed the lowest antiradical (AR) and total polyphenolic content (TPC) for the pomegranate tannin but also the highest AR/TPC ratio suggesting a good radical scavenging potential of this new tannin. Pomegranate tannin showed high reactivity with proteins, a unique chromatographic profile, and a low color impact. The new pomegranate tannin showed an interesting potential for oenological applications in particular for reducing the use of sulfites during vinification and for the white wine stabilization.
\end{abstract}

Keywords: polyphenols; ellagitannins; punicalagins; oenotannins; winemaking; by-products re-use; HPLC-DAD-MS; CIELab analysis; quality control; antioxidant capacity

\section{Introduction}

The International Organization of Vine and Wine (OIV) authorized the use of oenological tannins to facilitate the clarification of wines and musts as long as they do not change the olfactory properties and the color of the wine [1]. Beyond this authorized use, nowadays oenotannins are commonly used in winemaking for other properties, classifiable in 5 main groups [2]: (i) impact on oxygen/metals: protection of wine from oxidation, anti-laccase activity, superoxide radicals scavenger, direct consumption of dissolved oxygen, iron-chelating ability and capability of preventing oxidative damages through Fenton-based reaction [3-11]; (ii) impact on color/pigments: improvement and stabilization of color in red wine, triggering for formation of new pigments and co-pigmentation 
effect [12-15]; (iii) protein interaction and preventing protein haze [16,17]; (iv) sensory/mouthfeel properties: capability of improving wine structure and mouthfeel (particularly bitterness and astringency) and of eliminating reduction odors [18,19]; (v) bacteriostatic effects [20].

Several types of oenological tannins are present in the market mainly differing in chemical structure, botanical origin, and/or preparation process. These include (i) hydrolyzable tannins, as gallotannins from oak galls, tara, myrabolan fruits, and nut galls, and ellagitannins from chestnut and oak; (ii) condensed tannins from grape seeds and skins, mimosa, quebracho, and acacia $[2,11,12,15]$.

From the chemical point of view, condensed tannins (or proanthocyanidins) are polyhydroxyflavan-3-ol oligomers and polymers in which the flavanol subunits are linked through C-C bonds [21]. Hydrolyzable tannins are constituted of a glucose unit esterified by gallic acid moieties [22,23]. These, according to Okuda classification, are sub-classified as follow: gallotannins, characterized by several galloyl units linked each other by depside bonds (type-I hydrolyzable tannins) [24,25]; the intra- and/or intermolecular oxidative phenolic coupling to form C-C diaryland C-O diaryl- ether bonds between different galloyl residues gives rise to the formation of more than 1000 natural ellagitannins [26]. Ellagitannins are in turn divided into several sub-classes: type-II hydrolyzable tannins, characterized by the hexahydroxydiphenoyl (HHDP) group; type-III hydrolyzable tannins, characterized by dehydrohexahydroxydiphenoyl (DHHDP) group; type-IV hydrolyzable tannins, bearing for example the chebuloyl or elaeocarpusoyl groups; the $C$-glycosidic ellagitannins, in which the D-glucopyranose core is open and presents $C$-arylglucosidic bonds with galloyl-derived unit (as vescalagin and castalagin) [27]. The class of gallagyl esters presents the tetraphenyl ellagic acid-derived bislactone biester group (named gallagyl unit) as in pomegranate ellagitannins punicalin and punicalagins [27,28]. Complex tannins (or flavano-ellagitannins) are hydrolyzable tannins with a C-glucosidic ellagitannin moiety and a flavan-3-ol moiety. Finally, oligomeric ellagitannins can be formed through intermolecular $\mathrm{C}-\mathrm{O}$ oxidative coupling between different groups in two monomers [22,23,29].

Depending on their chemical structure, the different oenotannins explain different mechanisms of action and different properties. Both condensed and hydrolyzable tannins have the capability to interact with proteins forming soluble and insoluble complexes, but with a different mechanism of action. Condensed tannins are well-recognized for their capability of reacting, directly or by means of acetaldehyde-mediated reactions, with anthocyanins in wines, forming stable polymeric pigments, thus resulting in enhancing color stability against oxidation during red wine aging [15]. Hydrolyzable tannins, and particularly ellagitannins, are able to regulate oxidation, to quickly react with dissolved oxygen, and to facilitate the hydroperoxidation of wine constituents inducing tannin/anthocyanin condensation, thus enhancing color stabilization and deepening the crimson color [12]. Ellagitannins have been reported as the most effective oenotannins in protecting wine against chemical oxidation $[2,30]$. The ellagitannin vescalagin reacts with the red-colored anthocyanin oenin (a grape pigment) to provide a purple-colored anthocyanin-ellagitannin pigment [31], suggesting the capability of ellagitannins to directly react with anthocyanins. Recently, hydrolyzable tannins also showed a high reactivity in co-pigmentation reactions with anthocyanins in wine [32].

Pomegranate tree (Punica granatum L., Punicaceae family) is native to central Asia, and thanks to its high adaptivity to a wide range of climates and soil conditions, it grows in many different geographical regions worldwide. Iran and India, but also America and the Mediterranean regions, are the main producers $[33,34]$. The demand for pomegranate keeps increasing year after year, also thanks to the increasing consumer awareness about the health benefits related to the pomegranate consumption, mainly in the form of juice [35-40]. Indeed, thanks to its high antioxidant capacity, pomegranate as a polyphenol-rich fruit is being commonly referred to as "superfruit" [28,41]. The edible part of the fruit consists of arils, mainly used for juice extraction, while the nonedible one, namely the peels (exocarp + mesocarp), accounts for approx. $40-50 \%$ of the total fresh fruit weight and to date it is usually discarded thus constituting the main by-product of juice extraction. In the recent years, the interest of the scientific community is focused not only on the characterization of the chemical constituents of 
the edible parts but also on the nonedible ones, in order to evaluate any possibility of re-using these parts [34,42]. If the arils juices are rich in anthocyanins [28,42], the fresh peel is constituted by $\approx 70 \%$ of water, high amounts of simple sugars, polysaccharides, and hydrolyzable tannins [28,43-45]. Overall, hydrolyzable tannins, mainly found in peels, is the predominant class of phenols into fruit, with very high amounts of ellagitannins of the gallagyl esters class, as punicalins and punicalagins [28,42]. These latter have been strongly correlated to the antioxidant capacity [28].

Among the hundreds of pomegranate varieties spread worldwide, Wonderful is one of the main cultivated throughout Europe [34]. In a recent study, it was highlighted the presence of high amounts of ellagitannins into the peels of this variety, mainly involving $\alpha$ - and $\beta$-punicalagins and 3 punicalagins' derivatives [28]. The presence of this high content of ellagitannins suggests proposing the use of pomegranate peel extract as oenotannins aimed at improving the winemaking process.

The objective of this work was a preliminary evaluation of the suitability of a new pomegranate tannin extracted from mesocarp of the Wonderful variety for oenological applications. To this aim, a decoction from the fruit mesocarp was obtained and compared with several commercial oenotannins with different botanical origins.

\section{Results and Discussion}

The decoction obtained from the dried mesocarp of pomegranate fruit of the Wonderful variety was preliminarily analyzed in order to propose it for different applications. The proximate composition of the dried decoction was as follows: proteins $2.3 \%$, total sugar $45.0 \%$, total dietary fiber (measured with the AOAC 991.43 method) $9.7 \%$ (soluble 6.7\%, insoluble 3.0\%), while fats were not present in detectable amount, as expected. The content of ellagitannin was approximately $15 \%$, almost completely represented by $\alpha+\beta$ punicalagins, ellagic acid, and $\alpha+\beta$ punicalins, as highlighted by Figure 1 , showing the chromatographic profile at $370 \mathrm{~nm}$ obtained through analysis of the pomegranate dried extract by HPLC coupled Diode Array Detector and Mass Spectrometer Detector (HPLC-DAD-MS) (Figure 1).

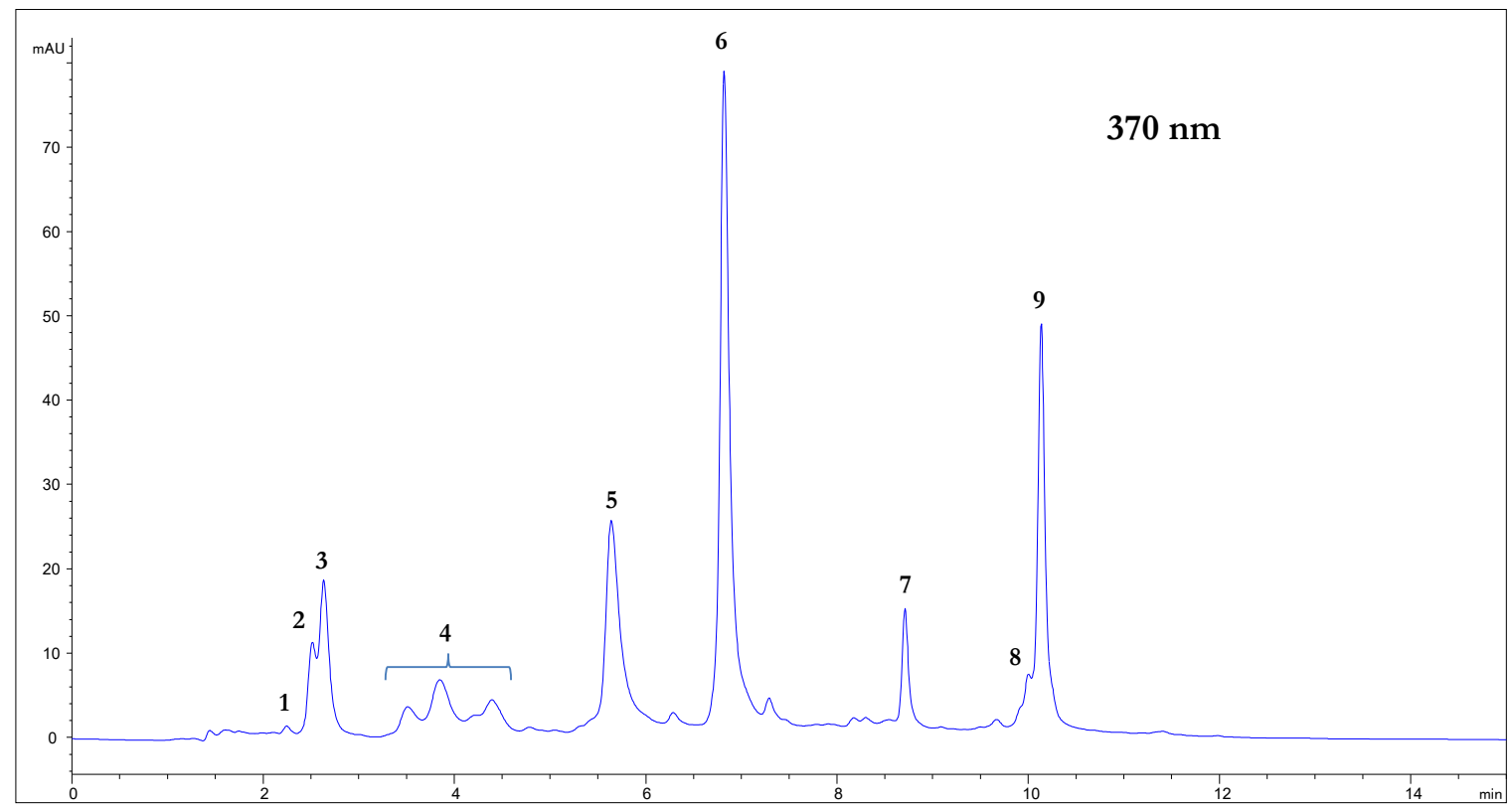

Figure 1. Chromatographic profiles at $370 \mathrm{~nm}$ of dried decoction with the main identified peaks: 1 , gallic acid (identified in the chromatogram at $280 \mathrm{~nm}$ ); 2, $\alpha$-punicalin; 3, $\beta$-punicalin; 4, punicalagin derivatives; 5 , $\alpha$-punicalagin; $6, \beta$-punicalagin; 7 , ellagic acid hexoside; 8 , ellagic acid pentoside; 9 , ellagic acid. 
A first comparison of the crude pomegranate tannin (TP) with the 7 commercial oenotannins (all listed in Table 1) of different botanical origin was based on their antioxidant and antiradical activities. Results of total phenolic content by Folin-Ciocalteu assay (TPC), total polyphenol index (TPI), and antiradical activity (AA) evaluated with 2,2-diphenyl-1-picrylhydrazyl (DPPH) are reported in Table 2, together with sample name, given code, and type of tannins. The AA/TPC ratio was also calculated in order to evaluate the antiradical activity on the basis of the total phenolic content.

Table 1. List of the analyzed tannins. For each tannin, the given code, the botanical origin, and the type of tannin are also reported.

\begin{tabular}{cccc}
\hline Tannin Name & Code & Botanical Origin & Type of Tannin \\
\hline Pomegranate tannin & TP & Pomegranate & Hydrolyzable (Ellagic) \\
Condensed \\
Grape seed tannin & TGS & Grape seed & Gacyanidin) \\
Nut gall tannin & TNG & Nut gall & Oak \\
Oak tannin 1 & TOAK1 & Oak & Hydrolyzable (Ellagic) \\
Oak tannin 2 & TOAK2 & Oak & Hydrolyzable (Ellagic) \\
Oak tannin 3 & TOAK3 & Oak & Hydrolyzable (Ellagic) \\
Oak tannin 4 & TOAK4 & Oak & Hydrolyzable (Ellagic) \\
Oak tannin 5 & TOAK5 &
\end{tabular}

Table 2. Antioxidant and antiradical activity of the analyzed tannins dissolved in the model wine solution. TPC: total phenolic content; TPI, total polyphenolic index; AA, antiradical activity evaluated using 2,2-diphenyl-1-picrylhydrazyl. Data are expressed as mean of three determinations; in each column, different letters (a-f) indicate statistically significant differences. F-values, $p$-values, and standard errors of means are also reported.

\begin{tabular}{ccccc}
\hline \multirow{2}{*}{ Sample Code } & $\begin{array}{c}\text { TPC }(\mathbf{m g} \text { gallic } \\
\mathbf{a c i d} / \mathbf{g})\end{array}$ & TPI (Abs $\mathbf{2 8 0 \mathbf { n m } )}$ & AA (\%) & AA/TPC \\
\hline TP & $273 \mathrm{a}$ & $7.62 \mathrm{a}$ & $68.2 \mathrm{a}$ & 0.25 \\
TGS & $601 \mathrm{c}$ & $15.38 \mathrm{c}$ & $79.5 \mathrm{~b}$ & 0.13 \\
TNG & $820 \mathrm{e}$ & $26.64 \mathrm{~h}$ & $93.7 \mathrm{e}$ & 0.11 \\
TOAK1 & $608 \mathrm{~cd}$ & $18.33 \mathrm{e}$ & $92.6 \mathrm{de}$ & 0.15 \\
TOAK2 & $482 \mathrm{~b}$ & $14.26 \mathrm{~b}$ & $83.1 \mathrm{c}$ & 0.17 \\
TOAK3 & $693 \mathrm{~d}$ & $21.45 \mathrm{~g}$ & $91.5 \mathrm{de}$ & 0.13 \\
TOAK4 & $690 \mathrm{~d}$ & $18.70 \mathrm{f}$ & $90.6 \mathrm{~d}$ & 0.13 \\
TOAK5 & $585 \mathrm{c}$ & $18.00 \mathrm{~d}$ & $92.5 \mathrm{de}$ & 0.16 \\
\hline F-value & 126.06 & 31124 & 97.28 & \\
$p$-value & $<0.0001$ & $<0.0001$ & $<0.0001$ & 1.17 \\
Standard error & 14.52 & 0.0002 & & \\
\hline
\end{tabular}

The total phenolic content of TP was the lowest $(273 \mathrm{mg} / \mathrm{g})$, with the other tannins showed an average of $640 \mathrm{mg} / \mathrm{g}$ and the TNG sample as the one with the highest value $(820 \mathrm{mg} / \mathrm{g})$. The TPI reflects the same trend of TPC, with the TP that showed the lowest value (7.62) and TNG the highest one (26.64). The AA\% shows the antiradicalic activity of the different oenological tannins according to the botanical origin: before measuring $\mathrm{AA} \%$ of the tannins, we also measured the AA\% of the model wine solution with no addition of any tannin, obtaining $2 \%$ of antiradical activity, this datum indicating that data in Table 2 (all higher than 68\%) are due to tannins. The TNG showed the highest antiradical activity (93.7\%), followed by the ellagic tannins, which showed an average value of $90.1 \%$; finally, the TGS (79.5\%) and the TP (68.2\%) showed the lowest values. Despite this evidences, TP showed the highest AA/TPC ratio value of 0.25 , indicating a higher reactivity of the pomegranate polyphenols against radicals in comparison to those of the other commercial tannins; on the opposite, the TNG, showing the highest TPC, is characterized by the lowest AA/TPC ratio. These evidences point out the possible use of these tannins during several phases of white, rosé, and red wine production, such as 
pre-fermentation, fermentation, aging, and so on. The wide variability of total phenols according to the botanical origin, and the highest TPC and AA activity showed by the TNG, are in agreement with previous literature $[2,5,11]$.

All the 7 commercial tannins and the pomegranate tannin were also analyzed by RP-HPLC-DAD in order to compare the different phenolic composition. The used chromatographic method provides chromatograms that allow evidencing the monomeric and oligomeric phenols and the polymeric tannins (Figure 2, peak at $65 \mathrm{~min}$ ), a method already used for analyzing oenotannins [12] and pigmented polymers in red wines [46]. Figure 2 shows the chromatograms registered at $280 \mathrm{~nm}$ of the eight different tannins. The different botanical origins can be immediately argued by observing the chromatograms: the ellagitannins showed very similar profiles among each other, with a lower content of polymeric tannins when compared to TNG. In fact, the polymeric tannins in TNG showed a chromatographic peak (peak $\mathrm{n}^{\circ} 10$ ) approximately 9 times greater compared to the tannins extracted from oak. The profile of the TGS was different from all the other ones and characterized by the presence of $(+)$-catechin, (-)-epicatechin, and procyanidins B1 and B2, very typical for a condensed tannin derived from grape, and by a moderate content in polymeric tannins. These findings are in agreement with previous literature [12]. As concerns the pomegranate tannin (TP), a very particular profile was evidenced as already described above: TP was composed by a lower content of polymeric tannins compared to all the others commercial products, very similar to the ellagic tannins, but higher in ellagitannins of the gallagyl type, characterized by a lower molecular weight [28].

The above different composition of tannins is in agreement with the literature [47] and is able to cause different properties linked to a different reactivity of the molecules. For example, the capability of tannins to precipitate proteins depending on the protein to tannin ratio and on the type of tannins is well-known [15]. For this reasons, the pomegranate tannin was compared to the 7 commercial products for its capability in precipitating bovine serum albumin (BSA): the higher the capability in precipitating BSA, the higher the protein stabilization capability of the tannin when added to wine and the greater the astringency [47]. The different reactivity with proteins was evaluated with two different approaches: (i) the typical gelatin index, which is the more used despite several other approaches have been proposed over time $[47,48]$; (ii) the measurement of the evolution of turbidity after addition of BSA to the tannin solution for the evaluation of the capability of both helping in protein fining and preventing protein haze [16]. The evolution of turbidity is shown by the curves in Figure 3, which also reports the $\triangle$ NTU (Nephelometric Turbidity Unit), calculated as the difference between turbidity before protein addition to the tannin solutions and turbidity after stabilization (i.e., approximately 900 s). It is interesting to highlight the wide variability in the observed $\triangle N T U$ values: overall, the oak tannins are the more reactive ones with $\triangle N T U$ in the range 259.2-183.2 (with the exception of TOAK2, with $\triangle N T U$ of 87.3). The TNG is quite lower than the oak tannins and with a value (135.4) similar to the TGS (124.2). Finally, the TP extract was the less reactive one with a $\triangle N T U$ of 30.1 ; the result about TP has to be related to its not so high phenolic concentration, probably due to the non-purified character of TP extract. Despite this lower $\triangle$ NTU of TP, Figure 4 shows that the gelatin index of TP was one of the highest, together with TGS and TOAK3, indicating a high reactivity of TP polyphenols and a consequent potentiality as a suitable oenotannin after optimizing its purification. This high reactivity, likely due to the lower molecular weight of TP polyphenols than those of the other commercial tannins, will make it necessary to evaluate the impact of TP in astringency perception after addition to wine [48]. 

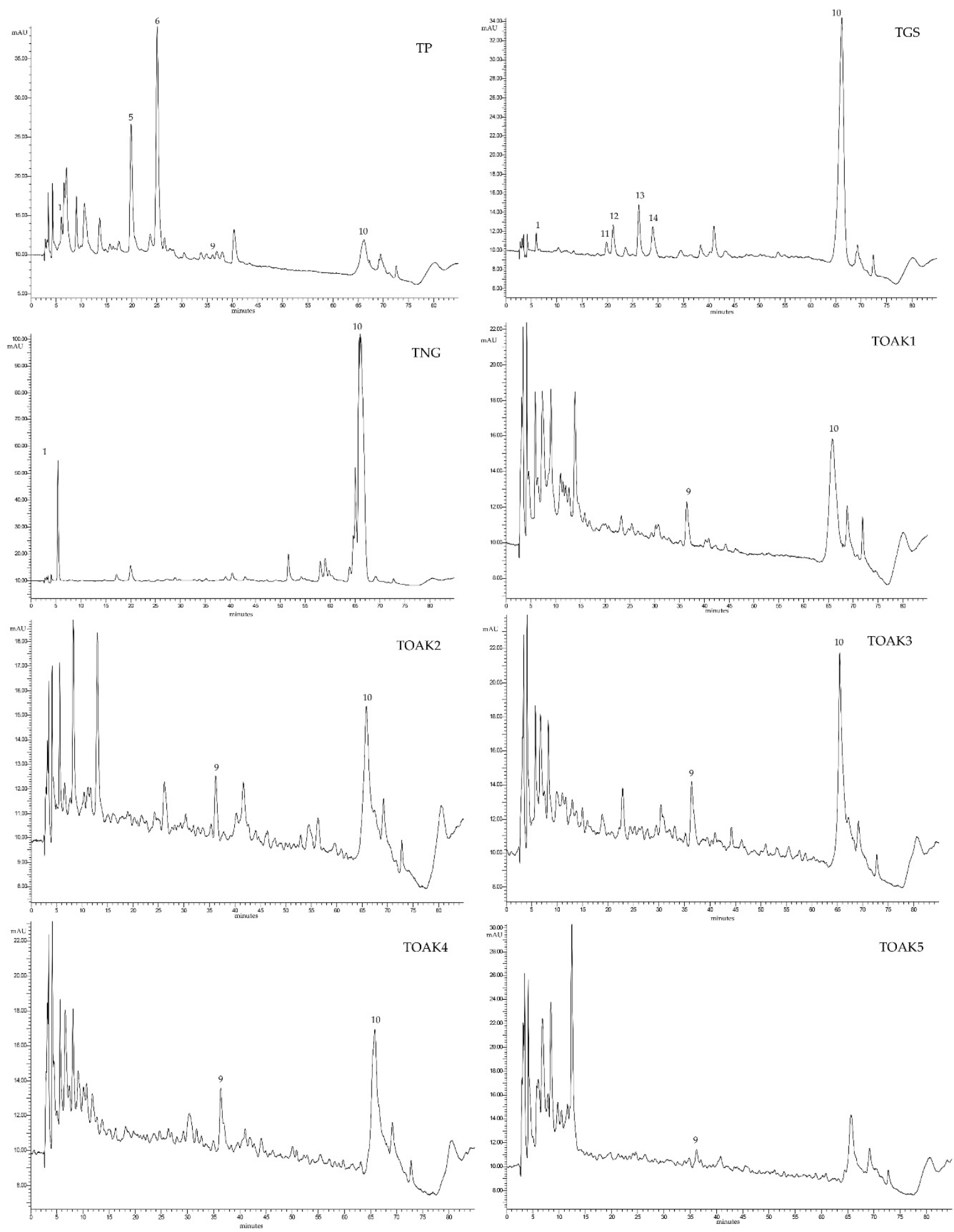

Figure 2. Chromatographic profiles at $280 \mathrm{~nm}$ of tannins in model wine solutions with the main peaks identified: 1 , gallic acid; $5, \alpha$-punicalagin; 6 , $\beta$-punicalagin; 9 , ellagic acid; 10 , polymeric tannins; 11 , procyanidin B1; 12, (+)-catechin; 13, (-)-epicatechin; 14, procyanidin B2. TP, Pomegranate tannin; TGS, grape seed tannin; TNG, Nut gall tannin; TOAK1-5, Oak tannin 1-5. 


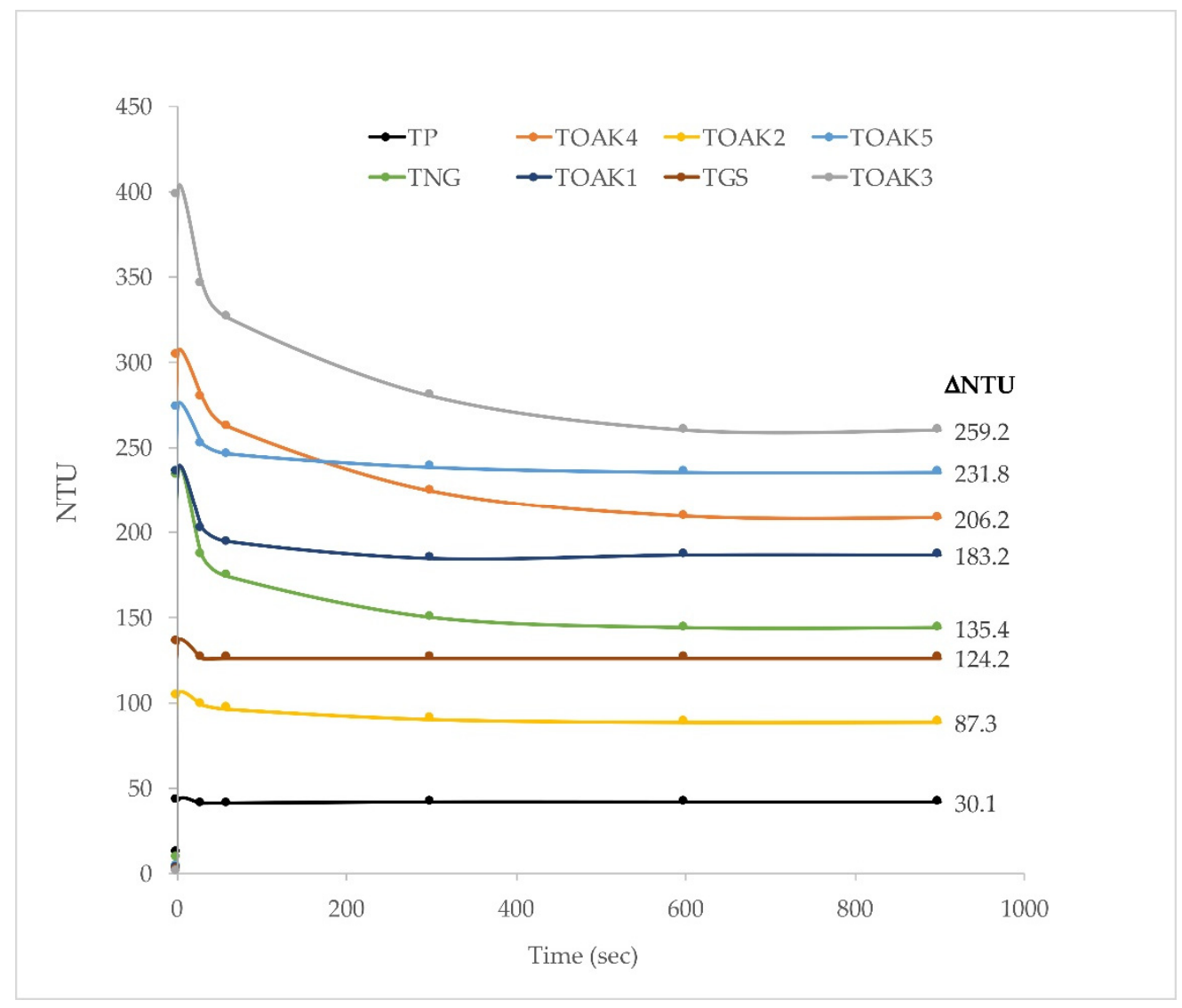

Figure 3. Reaction kinetics of the analyzed tannins dissolved in the model wine solution with gelatin from bovine serum albumin, and $\triangle$ NTU (nephelometric turbidity unit). Pomegranate tannin; TGS, grape seed tannin; TNG, Nut gall tannin; TOAK1, TOAK2, TOAK3, TOAK4, TOAK5, Oak tannin $1-5$, respectively.

In the next step of the study, we performed the color analysis in order to complete the characterization of the nature of the 8 different tannins. In fact, the UV-Vis spectroscopy is currently widely used to analyze oenotannins in order to differentiate them according to the botanical origin [49], while the CIEL $\mathrm{a}^{*} \mathrm{~b}^{*}$ analysis is used to describe the color of the analyzed powder since the addition of tannins to wine might affect the color, which is not permitted by regulation $[1,50]$. Figure 5 reports the UV-Vis spectra of the 8 analyzed tannins: the TP showed minimum absorbances $\left(\lambda_{\min }\right)$ at $243 \mathrm{~nm}$ and $339 \mathrm{~nm}$ and maximum absorbances $\left(\lambda_{\max }\right)$ at $254 \mathrm{~nm}$ and $372 \mathrm{~nm}$, with the latter being very close to the typical $\lambda_{\max }$ of punicalagins [28], in agreement with the polyphenolic profile above discussed. This profile is quite different from all the other 7 commercial tannins and also to other tannins reported in the literature [49], confirming that if this new tannin will be commercialized after purifaction it will be a diverse and easily recognizable oenotannin with respect to the existing commercial ones. Interestingly, all samples showed a very low absorbance starting from $420 \mathrm{~nm}$, thus not affecting the color properties of wines in the visible region. As concern TP, despite the $\lambda_{\max }$ at $372 \mathrm{~nm}$, it showed absorbance at $420 \mathrm{~nm}$ even lower than all the other tannins with the exception of TNG. Even considering a possible three-time increase of polyphenols concentration in TP (Table 2) after optimizing purification, and assuming a proportional increase of absorbance, the absorbance at $420 \mathrm{~nm}$ would remain lower than some of the analyzed commercial tannins. 


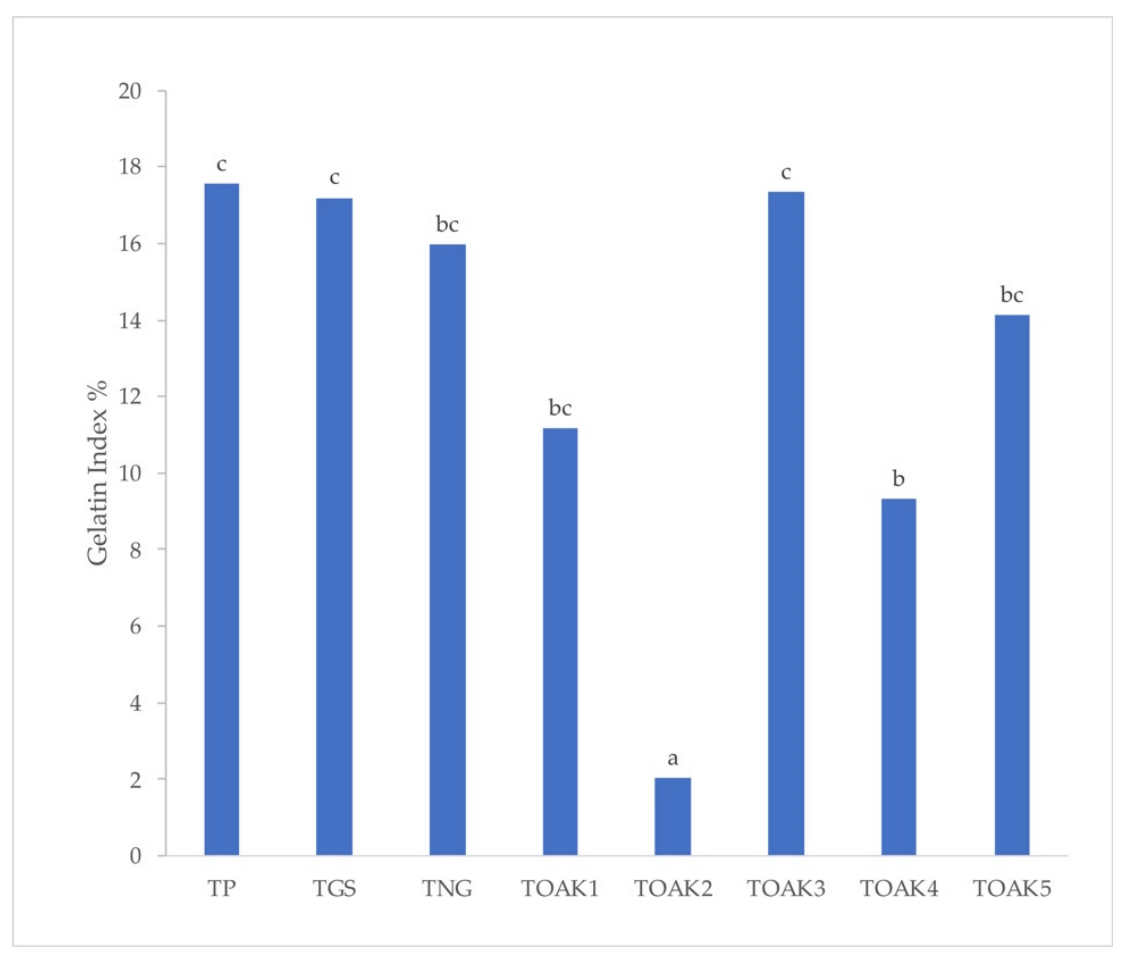

Figure 4. Gelatin index for the analyzed tannins dissolved in the model wine solution. Different letters indicate significant difference at $p$-value $<0.05$. TP, Pomegranate tannin; TGS, grape seed tannin; TNG, Nut gall tannin; TOAK1-5, Oak tannin 1-5, respectively.

The CIEL $\mathrm{a}^{*} \mathrm{~b}^{*}$ analysis has been carried out in order to better describe the color contribution of TP with respect to the other tannins. In fact, oenological tannins are well-recognized to be characterized by powders with quite different colors, for example ranging from pale-yellow to reddish-brown, which can differently affect the wines' characteristics [51]. As shown in Figure 6, the TP is again quite differentiable from all the other tannins, with the more similar one being the TNG, in agreement with the above described UV-Vis spectra. In fact, the TP and TNG showed similar $\mathrm{L}^{*}$ and $\mathrm{b}^{*}$ coordinates, differing in a significant manner only for the $\mathrm{a}^{*}$ coordinate, and resulting the less intense in color, as evidenced by the image of the eight solutions in Figure 6. This characteristic is very important since they would only slightly affect the wine color when added during production, in particular of white wines and spirits (i.e., grappa or brandy). 


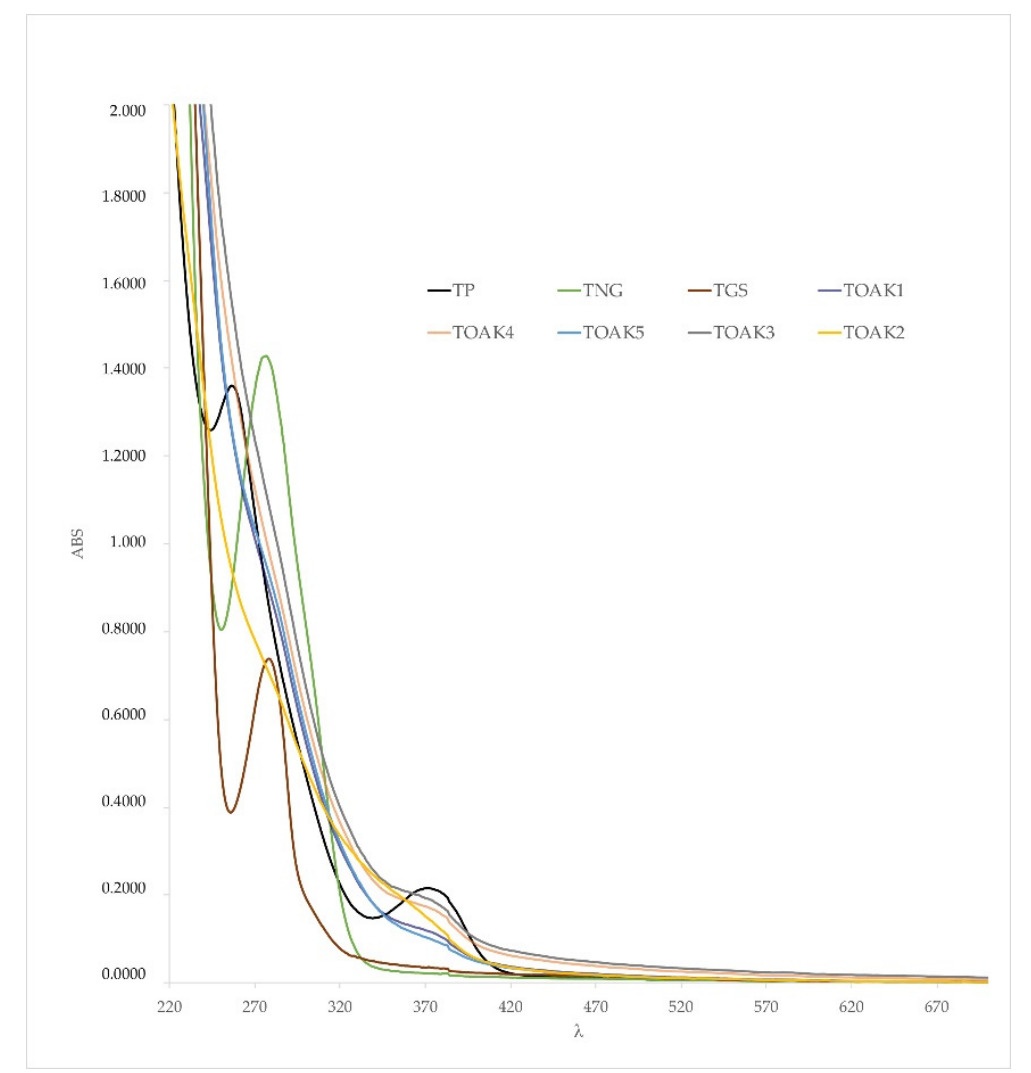

Figure 5. UV-Vis spectra of the analyzed tannins dissolved in the model wine solution. Pomegranate tannin; TGS, grape seed tannin; TNG, Nut gall tannin; TOAK1, TOAK2, TOAK3, TOAK4, TOAK5, Oak tannin $1-5$, respectively.

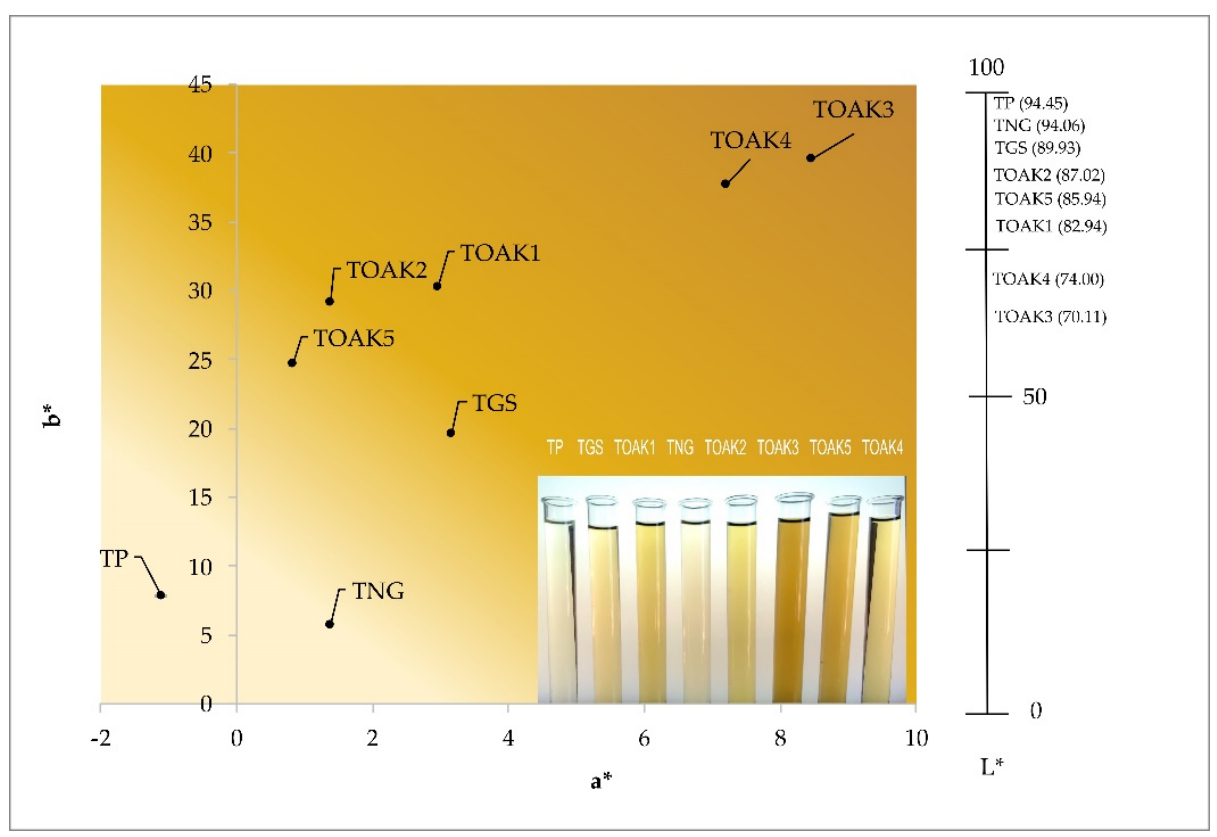

Figure 6. CIEL* $\mathrm{a}^{*} \mathrm{~b}^{*}$ coordinates of the analyzed tannins dissolved in the model wine solution. The 2D graph in the left reports the $a^{*}$ and $b^{*}$ coordinates, while the 1D axe in the right part reports the $L^{*}$ coordinate. An image of the analyzed tannin solutions is also shown in the bottom-right part of the 2D diagram. TP, Pomegranate tannin; TGS, grape seed tannin; TNG, Nut gall tannin; TOAK1-5, Oak tannin $1-5$, respectively. 


\section{Materials and Methods}

\subsection{Chemicals}

The Milli-Q-system (Millipore SA, Molsheim, France) was used to produce ultrapure water. Acetonitrile of both HPLC and HPLC-MS grades were purchased from Panreac (Barcelona, Spain). Formic acid and ethanol of analytical reagent grade were from Sigma-Aldrich (Steinheim, Germany). (+)-Catechin, (-)-epicatechin, procyanidin B1 and B2 were high in purity and purchased from Extrasynthèse (Genay, France). L-tartaric acid 99.5\%, sodium carbonate $\geq 95 \%$, Bovine Serum Albumin (BSA, $\geq 98 \%$ ), gallic acid monohydrate $\geq 98 \%, \alpha+\beta$ punicalagin $\geq 90 \%$, ellagic acid $\geq 95 \%$, 1,1-diphenyl-2-picrylhydrazyl radical (DPPH), and Folin-Ciocalteu reagent were purchased from Sigma-Aldrich (St. Louis, MO, USA). Polyvinylpolypyrrolidone (PVPP) was purchased from Enolife (Montemesola, Taranto, Italy). Seven commercial tannins were used in this study in addition to the new tannin from pomegranate (Table 1): one of the proanthocyanidin type (procyanidins/prodelphinidins from grape seed), and 6 hydrolyzable tannins among which one gallotannin from nut gall and 5 ellagitannins from oak.

\subsection{Preparation, Characterization, and Preliminarily Purification of the Decoction from Pomegranate Mesocarp} (Wonderful Variety)

Pomegranate fruit (Wonderful variety) were cultivated in Apulia region (Italy) and harvested in 2015. Mesocarp was manually separated from the other parts of the fruit (total $18 \mathrm{~kg}$ ). The mesocarp was constituted by $80 \%$ of moisture and was used to prepare a decoction [38]: briefly, mesocarp was boiled in water for $60 \mathrm{~min}$ using an extractive ratio mesocarp/water of 1:40 w/v. The obtained mixture was cooled at room temperature, centrifuged for $2 \mathrm{~min}$ at $5000 \mathrm{rpm}$, and filtered; the solution was freeze-dried, thus obtaining a dried product (TP, Table 1) easily storable and usable in the powder form. The final yield of the extract was $75 \%$ on the dried mesocarp basis.

The proximate composition of the dried decoction was evaluated according to the following analysis: the Kjeldahl method was applied for determination of the protein content $(\mathrm{PC}=\mathrm{N} \times 6.25$, where $\mathrm{N}$ is the total nitrogen and PC is the protein content in $\mathrm{g} / 100 \mathrm{~g}$ ); the content of fat was gravimetrically determined after Soxhlet extraction according to protocol ISS $n^{\circ} 1996 / 34$; the soluble and insoluble dietary fiber was finally determined according to the method AOAC $\mathrm{n}^{\circ} 991.43$.

\subsection{Preparation of Solution of the 8 Analyzed Tannins in Model Wine Solution}

All tannins (the 7 commercial ones and the TP, Table 1) were dissolved in model wine solution as follow: $1 \mathrm{~g}$ of each tannin was dissolved in $1 \mathrm{~L}$ of the model wine solution constituted by ethanol (12\% $v / v)$ and $4 \mathrm{~g} / \mathrm{L}$ of L-tartaric acid in water, with $\mathrm{pH}$ adjusted to 3.5 with $\mathrm{NaOH}$.

\subsection{Evaluation of Total Phenolic Content}

\subsubsection{Folin-Ciocalteu Assay}

The Folin-Ciocalteu method [52], slightly modified [53], was used for determining the total phenolic content. Deionized water $(0.5 \mathrm{~mL})$ and the Folin-Ciocalteu reagent $(125 \mu \mathrm{L})$ were added in a $15 \mathrm{~mL}$ plastic flask together with $125 \mu \mathrm{L}$ of the diluted sample extract. After $6 \mathrm{~min}, 1.25 \mathrm{~mL}$ of $7 \%$ aqueous $\mathrm{Na}_{2} \mathrm{CO}_{3}$ solution was added, and the final volume was brought to $3 \mathrm{~mL}$ with water and the mixture was left for $90 \mathrm{~min}$. Absorption was measured at $760 \mathrm{~nm}$ against water as a blank. A calibration curve built with gallic acid (range 20 to $500 \mu \mathrm{g} \mathrm{mL} \mathrm{m}^{-1}, \mathrm{R}^{2}=0.9969$ ) was used for evaluating the amount of total phenolic compounds, which was expressed as gallic acid equivalents (GAE, mg gallic acid/g sample). 


\subsubsection{Total Polyphenols Index}

The total polyphenol index (TPI) was determined by measuring the $280 \mathrm{~nm}$ absorbance of a 1:100 dilution of tannin solutions with a spectrophotometer, using a $10 \mathrm{~mm}$ quartz cuvette and multiplying the absorbance value by 100 [54].

\subsection{Evaluation of Antiradical Activity by DPPH}

The DPPH• (1,1-diphenyl-2-picrylhydrazyl radical) assay was used for evaluating the free radical scavenging activity according to the procedure previously reported [55] and slightly modified. DPPH solution was prepared by dissolving $4 \mathrm{mg}$ of solid material in $100 \mathrm{~mL}$ of ethanol; the obtained solution was kept overnight at $4{ }^{\circ} \mathrm{C}$ without light exposure, then it was stored at $-20{ }^{\circ} \mathrm{C}$ and thawed at room temperature before use. One milliliter of sample solution (tannin in model wine) was mixed to $1 \mathrm{~mL}$ of an ethanolic solution of DPPH• $(0.004 \mathrm{~g} / 100 \mathrm{~mL})$ and the mixture kept at room temperature. Absorption was measured at $517 \mathrm{~nm}$ immediately and after 20 min using a Lambda 25 spectrophotometer (PerkinElmer, Waltham, MA, USA) versus an ethanol: $\mathrm{H}_{2} \mathrm{O}$ 50:50 solution as a blank. The same procedure was also performed adding $1 \mathrm{~mL}$ of model wine instead of sample solution to compare the antiradical activity of tannins with that of the model wine itself. The absorption of the DPPH• solution was checked daily. The antiradical activity was expressed as percentage of antiradical activity, using the following formula:

$$
\mathbf{A A}(\%)=\frac{\mathbf{A}_{\mathbf{t} 0}-\mathbf{A}_{\mathbf{t} 20}}{\mathbf{A}_{\mathbf{t} 0}} \times 100
$$

where $\mathrm{AA}(\%)$ is the antiradical activity, $\mathrm{At}_{0}$ is the absorbance at time 0 , and $\mathrm{At}_{20}$ is the absorbance after $20 \mathrm{~min}$.

\subsection{UV-Vis Spectroscopy}

UV-Vis spectra of tannins were acquired in the range 200-700 nm using a $1 \mathrm{~mm}$ quartz cuvette (spectrophotometer Lambda 35 UVNis; PerkinElmer).

\subsection{HPLC and HPLC-MS Analysis}

Oenotannin preparations were analyzed by HPLC by a previous developed method [46]. HPLC analysis was carried out on a 200 LC system equipped with autosampler and diode-array detector (PerkinElmer). Prior to injection, oenotannin extracts solutions were centrifuged $(13,148 \times g)$ and filtered at $0.22 \mu \mathrm{m}$. Injection volume was $20 \mu \mathrm{L}$, flow rate was $1 \mathrm{~mL} / \mathrm{min}$ with the following gradient of solvent A (aqueous 1.5\% (v/v) $\mathrm{H}_{3} \mathrm{PO}_{4}$ ) and solvent $\mathrm{B}\left(20 \%(\mathrm{v} / \mathrm{v})\right.$ solvent $\mathrm{A}$ in $\left.\mathrm{CH}_{3} \mathrm{CN}\right)$ : from 8 to $27 \%$ solvent $B$ in the first $55 \mathrm{~min}$, held isocratic at $27 \%$ from 55 to $59 \mathrm{~min}$, increased from $27 \%$ to $70 \%$ from 59 to $64 \mathrm{~min}$, held at $70 \%$ from 64 to $69 \mathrm{~min}$, and reduced to $8 \%$ from 70 to $76 \mathrm{~min}$. Chromatograms were acquired at $280 \mathrm{~nm}$, recorded, and processed using Total Chrome Navigator software (PerkinElmer). LC-MS analysis was also performed for analyzing the TP, following the method recently reported [56]: briefly, an HP 1260 MSD mass spectrometer provided with both DAD and MSD detectors, and with an API/electrospray interface (Agilent Technologies, Palo Alto, CA, USA), was used. Compounds were separated in a Kinetex 100 EC-C18 $(30 \times 3 \mathrm{~mm}, 2.6 \mu \mathrm{m}$, Agilent, USA) column. Solvent A was acetonitrile and solvent $\mathrm{B}$ was $\mathrm{H}_{2} \mathrm{O}$ acidified by $\mathrm{HCOOH}(3 \%, v / v)$. The elution was carried out as follows: 0-8 min, solvent A varied 5-25\%; 8-18 min, stayed at 25\%; 18-20 min varied 25-95\%; 20-26 min stayed at 95\%. Total analysis time, $28 \mathrm{~min}$; equilibration time, $10 \mathrm{~min}$; flow rate $0.4 \mathrm{~mL} / \mathrm{min}$. Injection volume was $2 \mu \mathrm{L}$. Chromatograms were recorded at 280, 370, 380, and $520 \mathrm{~nm}$. ESI parameters: nitrogen flow rate $10.5 \mathrm{~L} / \mathrm{min}$, drying gas temperature $350{ }^{\circ} \mathrm{C}$; nebulizer pressure, 1811 Torr; capillary voltage, $3500 \mathrm{~V}$. Acquisition was performed in full spectrum scan (range 100-2000 Th) in negative ion mode with fragmentor voltage was set at $70 \mathrm{~V}$ or $300 \mathrm{~V}$. 


\subsection{CIEL $L^{*} a^{*} b^{*}$ Coordinates}

CIE (Commission Internationale de $\mathrm{l}^{\prime}$ Eclairage) $\mathrm{L}^{*}, \mathrm{a}^{*}$ and $\mathrm{b}^{*}$ color coordinates were measured [57,58]. Visible spectra were recorded at 400-700 $\mathrm{nm}$ transmittance using a spectrophotometer Lambda 35 UVNis (PerkinElmer) equipped with the RSA-PE-20 Integrating Sphere accessory assembly (Labsphere, North Sutton, NH, USA). UV WinLab Software was used to record the spectra (version 2.85.04, PerkinElmer Inc.) and CIE $\mathrm{L}^{*} \mathrm{a}^{*} \mathrm{~b}^{*}$ color coordinates were calculated for the CIE illuminant D65 and $10^{\circ}$ standard observed conditions, using Color software (version 3.00, 2001, PerkinElmer Inc.). Samples transmittance was measured using a $1 \mathrm{~mm}$ quartz cuvette.

\subsection{Tannin Analysis by the OIV Method}

The TP was also analyzed according to the official OIV methods [1]. Total solids (TS), soluble solids (SS), and non-phenolic solids (NPS) were determined using an SPE column with polyvinylpolypyrrolidone (PVPP) according to the official method. A blank measurement (BK) was also taken by doing the same as for the NPS. The tannin richness (\%tannins) was estimated using the following equation:

$$
\% \text { Tannins }=(\mathrm{SS}-\mathrm{NPS}-\mathrm{BK}) / \mathrm{TS} \times 100
$$

\subsection{Gelatin Index and Turbidity}

All the oenological tannins were analyzed using the gelatin precipitation method [59]. Briefly, 4 $\mathrm{mL}$ of oenological tannin solutions were placed in two centrifuge tubes. Tube A (sample) received an addition of $0.4 \mathrm{~mL}$ of aqueous BSA solution $(7 \% w / v)$. Tube B (control) was prepared similarly, but the added BSA solution was replaced with water. After $24 \mathrm{~h}$ at room temperature, the two tubes were centrifuged, and the supernatants were diluted 1:100 with water and read at $280 \mathrm{~nm}$ in a $1 \mathrm{~cm}$ quartz cuvette, obtaining the absorbance values ( $\mathrm{A}_{0}$ for tube $\mathrm{B}$ diluted solution, $\mathrm{A}$ for tube A diluted solution). The gelatin index was calculated according to the following formula:

$$
\text { Gelatin Index }=\left(\left(\mathrm{A}_{0}-\mathrm{A}\right) / \mathrm{A}_{0}\right) \times 100
$$

This index gives information concerning the reactivity of the tannin: the higher the value, the higher the reactivity of the extract towards proteins.

The turbidity of Tube A was also measured before and after the addition of BSA solution and monitored for approximately $20 \mathrm{~min}$, until turbidity stabilization, using a HACH2100N turbidimeter.

\subsection{Statistical Analysis}

All analyses were carried out in triplicate and the results were expressed as mean values. One-way ANOVA was applied to verify the existence of significant differences between samples; when the presence of differences was confirmed, Fisher's LSD test was applied to differentiate between mean values.

\section{Conclusions}

In this work, an extract from pomegranate by-products obtained by a green decoction process was characterized and compared to a series of oenotannins with different botanical origins in order to explain its potential use as oenotannin.

The experimental data indicated that the raw pomegranate extract is a potential new oenological tannin with a different tannin composition compared to those commercially available so far, thus enlarging the variability of products available on the market. In fact, it is characterized by the presence of a peculiar class of ellagic tannins, namely those bearing the gallagyl group such as punicalins, punicalagins, and their derivatives. A high antiradical activity (almost 70\%) and a color profile suitable for winemaking have been pointed out. 
The raw extract should be purified in order to increase the polyphenols concentration for meeting the indication of the OIV. In fact, quantification of tannins by the OIV method showed that the total polyphenols content of the TP is quite low (approximately 15\%), in agreement with the total phenolic content measured with the Folin-Ciocalteu method $(273 \mathrm{mg} / \mathrm{g})$. The measured composition of the raw extract indicated that about half of its weight is constituted by sugars, thus removing them may allow for a strong increase of tannins concentration. In the next steps of the work, the extraction and purification processes of the pomegranate tannin will be optimized in order to obtain a product richer in ellagitannins and free from impurity.

The use of oenotannins in winemaking has received renewed attention, and the winemaking process itself is daily facing against the use of synthetic antioxidant as sulfites. In this context, this study pointed out the possibility of recovering added value from a by-product of pomegranate consumption giving to the enology a new possibility. The new extract would be useful in several steps of winemaking process for allowing improving the protein stability of white and rosé wines, enhancing the color stability, and reducing the use of sulfites thanks to its capability of protection from oxidation. The addition of the tannin will also result in a higher content of polyphenols, commonly associated with wines with a higher market value. Its use in the winemaking process has to be carefully studied in order to propose it for the list of admitted oenotannins.

Author Contributions: Conceptualization, N.M., L.G., and V.C.; methodology, L.C., L.G., and M.K.; formal analysis, V.C. and L.C.; investigation, B.Z. and V.C.; resources, V.C., B.Z., and N.M.; data curation, L.C. and V.C.; writing-original draft preparation, L.C. and V.C.; writing—review and editing, V.C., N.M., and B.Z.; visualization, M.K.; supervision, B.Z. and N.M.; project administration, N.M. and V.C.; funding acquisition, B.Z., V.C., and N.M. All authors have read and agreed to the published version of the manuscript.

Funding: This research received no external funding.

Conflicts of Interest: The authors declare no conflict of interest.

\section{References}

1. OIV. International Oenological Codex. COEI-1-TANINS: 2017. Available online: http://www.oiv.int/public/ medias/4093/e-coei-1-tanins.pdf (accessed on 24 August 2020).

2. Vignault, A.; Gonzalez-Centeno, M.R.; Pascual, O.; Gombau, J.; Jourdes, M.; Moine, V.; Iturmendi, N.; Canals, J.M.; Zamora, F.; Teissedre, P.L. Chemical characterization, antioxidant properties and oxygen consumption rate of 36 commercial oenological tannins in a model wine solution. Food Chem. 2018, 268, 210-219. [CrossRef] [PubMed]

3. Vignault, A.; Gombau, J.; Jourdes, M.; Moine, V.; Canals, J.M.; Fermaud, M.; Roudet, J.; Zamora, F.; Teissedre, P.L. Oenological tannins to prevent Botrytis cinerea damage in grapes and musts: Kinetics and electrophoresis characterization of laccase. Food Chem. 2020, 316, 126334. [CrossRef]

4. González-Centeno, M.R.; Jourdes, M.; Femenia, A.; Simal, S.; Rosselló, C.; Teissedre, P.-L. Proanthocyanidin composition and antioxidant potential of the stem Winemaking byproducts from 10 different grape varieties (Vitis vinifera L.). J. Agric. Food Chem. 2012, 60, 11850-11858. [CrossRef] [PubMed]

5. Magalhaes, L.M.; Ramos, I.I.; Reis, S.; Segundo, M.A. Antioxidant profile of commercial oenological tannins determined by multiple chemical assays. AJGW 2014, 20, 72-79. [CrossRef]

6. Obradovic, D.; Schulz, M.; Oatey, M. Addition of natural tannins to enhance the quality of red wine. In Australian E New Zealand Grapegrower \& Winemaker; WineMaker: Broadview, Australia, 2005; pp. 52-54.

7. Farhadi, K.; Esmaeilzadeh, F.; Hatami, M.; Forough, M.; Molaie, R. Determination of phenolic compounds content and antioxidant activity in skin, pulp, seed, cane and leaf of five native grape cultivars in West Azerbaijan province Iran. Food Chem. 2016, 199, 847-855. [CrossRef] [PubMed]

8. Perez, C.A.; Wei, Y.; Guo, M. Iron-binding and anti-Fenton properties of baicalein and baicalin. J. Inorg. Biochem. 2009, 103, 326-332. [CrossRef]

9. Karamać, M.; Pegg, R.B. Limitations of the tetramethylmurexide assay for investigating the Fe(II) chelation activity of phenolic compounds. J. Agric. Food Chem. 2009, 57, 6425-6431. [CrossRef] 
10. Navarro, M.; Kontoudakis, N.; Giordanengo, T.; Gómez-Alonso, S.; García-Romero, E.; Fort, F.; Canals, J.M.; Hermosín-Gutíerrez, I.; Zamora, F. Oxygen consumption by oak chips in a model wine solution; Influence of the botanical origin, toast level and ellagitannin content. Food Chem. 2016, 199, 822-827. [CrossRef]

11. Pascual, O.; Vignault, A.; Gombau, J.; Navarro, M.; Gomez-Alonso, S.; Garcia-Romero, E.; Canals, J.M.; Hermosin-Gutierrez, I.; Teissedre, P.L.; Zamora, F. Oxygen consumption rates by different oenological tannins in a model wine solution. Food Chem. 2017, 234, 26-32. [CrossRef]

12. Canuti, V.; Puccioni, S.; Giovani, G.; Salmi, M.; Rosi, I.; Bertuccioli, M. Effect of oenotannin addition on the composition of sangiovese wines from grapes with different characteristics. Am. J. Enol. Vitic. 2012, 63, 220-231. [CrossRef]

13. Trouillas, P.; Sancho-García, J.C.; De Freitas, V.; Gierschner, J.; Otyepka, M.; Dangles, O. Stabilizing and modulating color by copigmentation: Insights from theory and experiment. Chem. Rev. 2016, 116, 4937-4982. [CrossRef] [PubMed]

14. Neves, A.C.; Spranger, M.I.; Zhao, Y.Q.; Leandro, M.C.; Sun, B.S. Effect of addition of commercial grape seed tannins on phenolic composition, chromatic characteristics, and antioxidant activity of red wine. J. Agric. Food Chem. 2010, 58, 11775-11782. [CrossRef] [PubMed]

15. Versari, A.; du Toit, W.; Parpinello, G.P. Oenological tannins: A review. Aust. J. Grape Wine Res. 2013, 19, 1-10. [CrossRef]

16. Ribéreau-Gayon, P.; Dubourdieu, D.; Donèche, B. Handbook of Enology, 2nd ed.; Hoboken, N.J., Ed.; John Wiley: Chichester, UK, 2006.

17. Mierczynska-Vasilev, A.; Smith, P.A. Current state of knowledge and challenges in wine clarification. Aust. J. Grape Wine Res. 2015, 615-626. [CrossRef]

18. Preys, S.; Mazerolles, G.; Courcoux, P.; Samson, A.; Fischer, U.; Hanafi, M.; Bertran, D.; Cheynier, V. Relationship between polyphenolic composition and some sensory properties in red wines using multiway analyses. Anal. Chim. Acta 2006, 563, 126-136. [CrossRef]

19. Vivas, N.; Nonier, M.-F.; de Gaulejac, N.V.; Absalon, C.; Bertrand, A.; Mirabel, M. Differentiation of proanthocyanidin tannins from seeds, skins and stems of grapes (Vitis vinifera) and heartwood of Quebracho (Schinopsis balansae) by matrixassisted laser desorption/ionization time-of-flight mass spectrometry and thioacidolysis/liquid chromatography/electrospray ionization mass spectrometry. Anal. Chim. Acta 2004, 513, 247-256. [CrossRef]

20. Lempereur, V.; Blayteyron, L.; Labarbe, B.; Saucier, C.; Klebek, H.; Glories, Y. Groupe national de travail sur les tanins oenologiques: Premiers résultats. Rev. Française d'Oenologie Paris 2002, 196, 23-29.

21. Schofield, P.; Mbugua, D.M.; Pell, A.N. Analysis of condensed tannins: A review. Anim. Feed Sci. Technol. 2001, 91, 21-40. [CrossRef]

22. Jourdes, M.; Pouysegu, L.; Deffieux, D.; Teissedre, P.-L.; Quideau, S. Hydrolyzable tannins: Gallotannins and ellagitannins. In Natural Products: Phytochemistry, Botany and Metabolism of Alkaloids, Phenolics and Terpenes; Springer Link: New York, NY, USA, 2013; pp. 1795-2010. [CrossRef]

23. Yoshida, T.; Hatano, T.; Ito, H.; Okuda, T. Structural diversity and antimicrobial activities of ellagitannins. In Chemistry and Biology of Ellagitannins: An Underestimated Class of Bioactive Plant Polyphenols; World Scientific Publishing Co.: Singapore, 2009; pp. 55-93. [CrossRef]

24. Okuda, T.; Yoshida, T.; Hatano, T. Correlation of oxidative transformation of hydrolysable tannins and plant evolution. Phytochemistry 2000, 55, 513-529. [CrossRef]

25. Okuda, T.; Yoshida, T.; Hatano, T.; Ito, H. Ellagitannins renewed the concept of tannins. In Chemistry and Biology of Ellagitannins-An Underestimated Class of Bioactive Plant Polyphenols; Quideau, S., Ed.; Imperial College Press/World Scientific Publishing: Singapore, 2009. [CrossRef]

26. Yamada,H.; Wakamori, S.; Hirokane, T.; Ikeuchi, K.; Matsumoto, S. Structural revisions in natural ellagitannins. Molecules 2018, 23, 1901. [CrossRef]

27. Landete, J.M. Ellagitannins, ellagic acid and their derived metabolites: A review about source, metabolism, functions and health. Food Res. Int. 2011, 44, 1150-1160. [CrossRef]

28. Fischer, U.A.; Carle, R.; Kammerer, D.R. Identification and quantification of phenolic compounds from pomegranate (Punica granatum L.) peel, mesocarp, aril and differently produced juices by HPLC-DAD-ESI/MS(n). Food Chem. 2011, 127, 807-821. [CrossRef] [PubMed]

29. Okuda, T.; Yoshida, T.; Hatano, T. Classification of oligomeric hydrolysable tannins and specificity of their occurrence in plants. Phytochemistry 1993, 32, 507-521. [CrossRef] 
30. Jeremic, J.; Vonglunngam, I.; Ricci, A.; Parpinello, G.P.; Versari, A. The Oxygen Consumption Kinetics of Commercial Oenological Tannins in Model Wine Solution and Chianti Red Wine. Molecules 2020, 25, 1215. [CrossRef] [PubMed]

31. Chassaing, S.; Lefeuvre, D.; Jacquet, R.; Jourdes, M.; Ducasse, L.; Galland, S.; Grelard, A.; Saucier, C.; Teissedre, P.-L.; Dangles, O.; et al. Physicochemical studies of new anthocyano-ellagitannin hybrid pigments: About the origin of the influence of oak C-glycosidic ellagitannins on wine color. Eur. J. Org. Chem. 2010, 1, 55-63. [CrossRef]

32. Vignault, A.; Gombau, J.; Pascual, O.; Jourdes, M.; Moine, V.; Canals, J.M.; Zamora, F.; Teissedre, P.L. Copigmentation of malvidin-3-O-monoglucoside by oenological tannins: Incidence on wine model color in function of botanical origin, $\mathrm{pH}$ and ethanol content. Molecules 2019, 24, 1448. [CrossRef]

33. Holland, D.; Hatib, K.; Bar-ya, I. Pomegranate: Botany, Horticulture, Breeding. Hort. Rev. 2009, 35, 127-192. [CrossRef]

34. Hussein, L.; Gouda, M.E.L. Pomegranate: Cultivation, Pomological Properties, Processing, Global Market and Health Benefits. Pomegranate: Cultivation, Antioxidant and Health Benefits; Food science and technology, Nova Science Publisher: New York, NY, USA, 2018; pp. 267-302.

35. Gil, M.I.; Tomas-Barberan, F.A.; Hess-Pierce, B.; Holcroft, D.M.; Kader, A.A. Antioxidant activity of pomegranate juice and its relationship with phenolic composition and processing. J. Agric. Food Chem. 2000, 48, 4581-4589. [CrossRef]

36. Scaioli, E.; Belluzzi, A.; Ricciardello, L.; Del Rio, D.; Rotondo, E.; Mena, P.; Derlindati, E.; Danesi, F. Pomegranate juice to reduce fecal calprotectin levels in inflammatory bowel disease patients with a high risk of clinical relapse: Study protocol for a randomized controlled trial. Trials 2019, 20, 327. [CrossRef]

37. Kujawska, M.; Jourdes, M.; Kuprik, M.; Szulc, M.; Szaefer, H.; Chmielarz, P.; Kreiner, G.; Krajka-Kuzniak, V.; Mikolajczak, P.L.; Teissedre, P.-L.; et al. Neuroprotective Effects of Pomegranate Juice against Parkinson's Disease and Presence of Ellagitannins-DerivedMetabolite-Urolithin A-In the Brain. Int. J. Mol. Sci. 2020, 21, 202. [CrossRef]

38. Tortora, K.; Femia, A.P.; Romagnoli, A.; Sineo, I.; Khatib, M.; Mulinacci, N.; Caderni, G. Pomegranate By-Products in Colorectal Cancer Chemoprevention: Effects in Apc-Mutated Pirc Rats and Mechanistic Studies In Vitro and Ex Vivo. Mol. Nutr. Food Res. 2018, 62, 1-10. [CrossRef]

39. Wu, Y.; Zhu, C.; Zhang, Y.; Li, Y.; Sun, J. Immunomodulatory and antioxidant effects of pomegranate peel polysaccharides on immunosuppressed mice. Int. J. Biol. Macromol. 2019, 137, 504-551. [CrossRef] [PubMed]

40. Parisio, C.; Lucarini, E.; Micheli, L.; Toti, A.; Khatib, M.; Mulinacci, N.; Calosi, L.; Bani, D.; di Cesare Mannelli, L.; Ghelardini, C. Pomegranate mesocarp against colitis-induced visceral pain in rats: Effects of a decoction and its fraction. Int. J. Mol. Sci. 2020, 21, 4304. [CrossRef] [PubMed]

41. Seeram, N.; Aviram, M.; Zhang, J.; Henning, S.; Feng, L.; Dreher, M.; Heber, D. Comparison of antioxidant potency of commonly consumed polyphenol-rich beverages in United States. J. Agric. Food Chem. 2008, 56, 1415-1422. [CrossRef] [PubMed]

42. Balli, D.; Cecchi, L.; Khatib, M.; Bellumori, M.; Cairone, F.; Carradori, S.; Zengin, G.; Cesa, S.; Innocenti, M.; Mulinacci, N. Characterization of Arils Juice and Peel Decoction of Fifteen Varieties of Punica granatum L.; A Focus on Anthocyanins, Ellagitannins and Polysaccharides. Antioxidants 2020, 9, 238. [CrossRef]

43. Singh, B.; Pal, J.; Kaur, A.; Singh, N. Phenolic compounds as beneficial phytochemicals in pomegranate (Punica granatum L.) peel: A review. Food Chem. 2018, 261, 75-86. [CrossRef]

44. Khatib, M.; Giuliani, C.; Rossi, F.; Adessi, A.; Al-Tamimi, A.; Mazzola, G.; Mulinacci, N. Polysaccharides from by-products of the Wonderful and Laffan pomegranate varieties: New insight into extraction and characterization. Food Chem. 2017, 235, 58-66. [CrossRef]

45. Talekar, S.; Patti, A.F.; Vijayraghavan, R.; Arora, A. An integrated green biorefinery approach towards simultaneous recovery of pectin and polyphenols coupled with bioethanol production from waste pomegranate peels. Bioresour. Technol. 2018, 266, 322-334. [CrossRef]

46. Peng, Z.; Iland, P.G.; Oberholster, A.; Sefton, M.A. Analysis of pigmented polymers in red wine by reverse phase HPLC. Aust. J. Grape Wine Res. 2002, 8, 70-75. [CrossRef]

47. Obreque-Slier, E.; Pena-Neira, A.; Lopez-Solis, R.; Ramirez-Escudero, C.; Zamora-Marin, F. Phenolic characterization of commercial enological tannins. Eur. Food Res. Technol. 2009, 229, 859-866. [CrossRef]

48. Herderich, M.J.; Smith, P.A. Analysis of grape and wine tannins: Methods, applications and challenges. Aust. J. Grape Wine Res. 2005, 11, 205-214. [CrossRef] 
49. Laghi, L.; Parpinello, G.P.; Del Rio, D.; Calani, L.; Mattioli, A.U.; Versari, A. Fingerprint of enological tannins by multiple techniques approach. Food Chem. 2010, 121, 783-788. [CrossRef]

50. Bertrand, A.; Vivas, N.; Kahn, N.; Caillet, M.M. Characterisation of proanthocyanidins from grapes and from the heartwood of quebracho. The tailored use of tannins. Asvo Proc.-Adv. Tann. Tann. Manag. 2012, 32-35.

51. Vivas, N. Diversità dei preparati commerciali di estratti vegetali ad uso enologico. In Prodotti di Trattamento ed Ausiliari di Elaborazione dei Mosti e dei Vini, 1st ed.; Bertrand, A., Canal-Llaubères, R.M., Feuillat, M., Hardy, G., Lamadon, F., Lonvaud-Funel, A., Pellerin, P., Vivas, N., Eds.; Eno-one: Reggio Emilia, Italy, 2002; pp. 143-163.

52. Singleton, V.L.; Orthofer, R.; Lamuela-Raventos, R.M. Analysis of total phenols and other oxidation substrates and antioxidants by means of the Folin-Ciocalteu reagent. Meth. Enzymol. 1999, 299, 152-178. [CrossRef]

53. Dewanto, V.; Wu, X.; Adom, K.K.; Liu, R.H. Thermal processing enhances the nutritional value of tomatoes by increasing total antioxidant activity. J. Agric. Food Chem. 2002, 50, 3010-3014. [CrossRef] [PubMed]

54. Ribereau-Gayon, P. Le dosage des composés phénoliques totaux dans les vins rouges. Chim. Anal. 1970, 52, 627-631. [CrossRef]

55. Brand-Williams, W.; Cuvelier, M.E. Use of a free radical method to evaluate the antioxidant activity. LWT-Food Sci. Technol. 1995, 28, 25-30. [CrossRef]

56. Balli, D.; Tozzi, F.; Khatib, M.; Adessi, A.; Malgarejo, P.; Masciandaro, G.; Giordani, E.; Innocenti, M.; Mulinacci, N. Purple Queen ${ }^{\circledR}$ fruits of Punica granatum L.: Nutraceutical properties and unconventional growing substrates. J. Berry Res. 2020, in press. [CrossRef]

57. del Alaya, F.; Echavarru, J.F.; Negueruela, A.I. A new simplified method for measuring the color of wines. I. Red and Rosé Wines. Am. J. Enol. Vitic. 1997, 48, 357-363.

58. CIE. Colorimetry, 2nd ed.; Publication CIE 15.2: Vienna, Austria, 1986.

59. Mirabel, M. Caracteristiques Chimiques et Organoleptiques des Tanins des Raisins de Vitis vinifera var. Merlot et Cabernet Sauvignon Issus de Differents Terroirs Bordelais. Ph.D. Thesis, Université Victor Segalen Bordeaux, Bordeaux, France, 2000.

Sample Availability: Not available.

(C) 2020 by the authors. Licensee MDPI, Basel, Switzerland. This article is an open access article distributed under the terms and conditions of the Creative Commons Attribution (CC BY) license (http://creativecommons.org/licenses/by/4.0/). 